\title{
Talent Management Strategy and its impact on Staff Development as a Foundation in Total Quality Management (TQM): Case Study of the Jordan Islamic Bank
}

\author{
Dr. HAMED OMAR ABDALLA \\ Researcher of Quality and strategic Mgt, Jordan. \\ Email: hamed.kanan@gmail.com \\ Dr. SULEIMAN ZAYED AL-NEIMAT \\ Researcher of Quality, Jordan
}

\begin{abstract}
The study aims to clarify the concept of talent management and its strategic components and to clarify the main dimensions of the process of staff development. It also aims to identify the effect of talent strategy and its sub-strategies on the process of staff development in the Jordan Islamic Bank. The study concludes many results, including that the effect level of the main talent strategy and the sub-strategies was positive and high. It recommends that the bank strategy should take into consideration the talent strategy which is found to be an important variable and a main requirement in the process of staff development.
\end{abstract}

Keywords: Strategy, Talent Management, Talent Localization, Values Building.

\section{Introduction}

The recent decades of focusing on human resources, especially in the implementation of TQM, and considering them as the real source of capital in all its intellectual, social and economic dimensions, have led the organizations to give serious and comprehensive attention to the management of their human resources and to develop the appropriate and necessary strategies to develop these resources, to invest them in a manner that would effectively realize their purposes and help them succeed in managing their competitive strategies.

One of the most important elements of the success of this endeavor is to develop an integrated strategy to manage the talented elements. That is by managing the recruitment process, in a way that ensures hiring the individuals, who have the talents required by the concerned organizations, and working, afterwards, on localizing and investing in them effectively, with an eye on retaining them to serve as the backbone of the organization that provides it with the strength and capacity, which are necessary for its survival and promotion.

This requires the development of a strategy to continuously develop these resources in order to achieve a value-based alignment between the values of the organization and the values of its staff, and hence, raise the knowledge and skills of the staff in accordance with the adopted system of values. That is to ensure that all the knowledge and technology developments in the world are absorbed in the necessary fields of work. 
The Islamic banking institutions, on top of which is Jordan Islamic Bank, are leading financial institutions that play an important role in the management of financial and economic life in the Jordanian society. Moreover, they are among the most important organizations that attract a significant number of employees.

The competitive process that is prevalent in the Jordanian market and other regional and international markets necessitates that these Islamic institutions develop appropriate strategies to manage their human resources to ensure their survival. This study is a scientific contribution that can help decision-makers take appropriate steps as they develop their strategies, especially those related to talent management and development.

\section{Significance of the study}

This importance stems from the fact that it deals with a new subject, and there is still a need for further research and enrichment of knowledge. It offers cognitive adaptations that can represent an additional building block in the knowledge structure of this subject. It is also an important attempt to understand the interrelationships between two core human resources topics in the context of TQM implementation and to measure their impact, giving them a practical value that decision makers in the organization can utilize to rationalize their decisions.

\section{Objectives of the study}

The main objective of the study is to identify the impact of the talent management strategy on the development process of the staff so as to help decision-makers in the concerned organization to give attention to it as they develop their strategies. This objective is derived from the following sub-goals:

1. Identifying the impact of talent recruitment strategy on the process of staff development

2. Identifying the impact of talent localization strategy on the process of staff development

3. Identifying the impact of talent investment strategy on the process of staff development

4. Identifying the impact of talent retention strategy on the process of staff development

\section{Statement of the Problem}

As with other organizations, banking organizations face real challenges. They work on developing their employees to create cultural (value-related) harmonization between their culture and system of values and their employees' culture and values. This is more important and urgent for Islamic organizations, as they are based on an integrated value system and they differ from what is prevalent in the contemporary societies.

That is in addition to following up on new and emerging knowledge and skills, and enabling the employees to absorb them. The organizations must work on overcoming and facing these challenges in a strategic and comprehensive manner. Perhaps, the development of a clear strategy for talent management on their part represents an important input in this direction, and it helps to achieve the desired successes.

\section{Study Model: It is based on two variables}

The independent variable: Talent management strategy, and it comprises the following sub-variables: (recruitment strategy, localization strategy, investment strategy and retention strategy).

The dependent variable: Staff development and it comprises the following sub-variables: values building, knowledge development, skills development). 


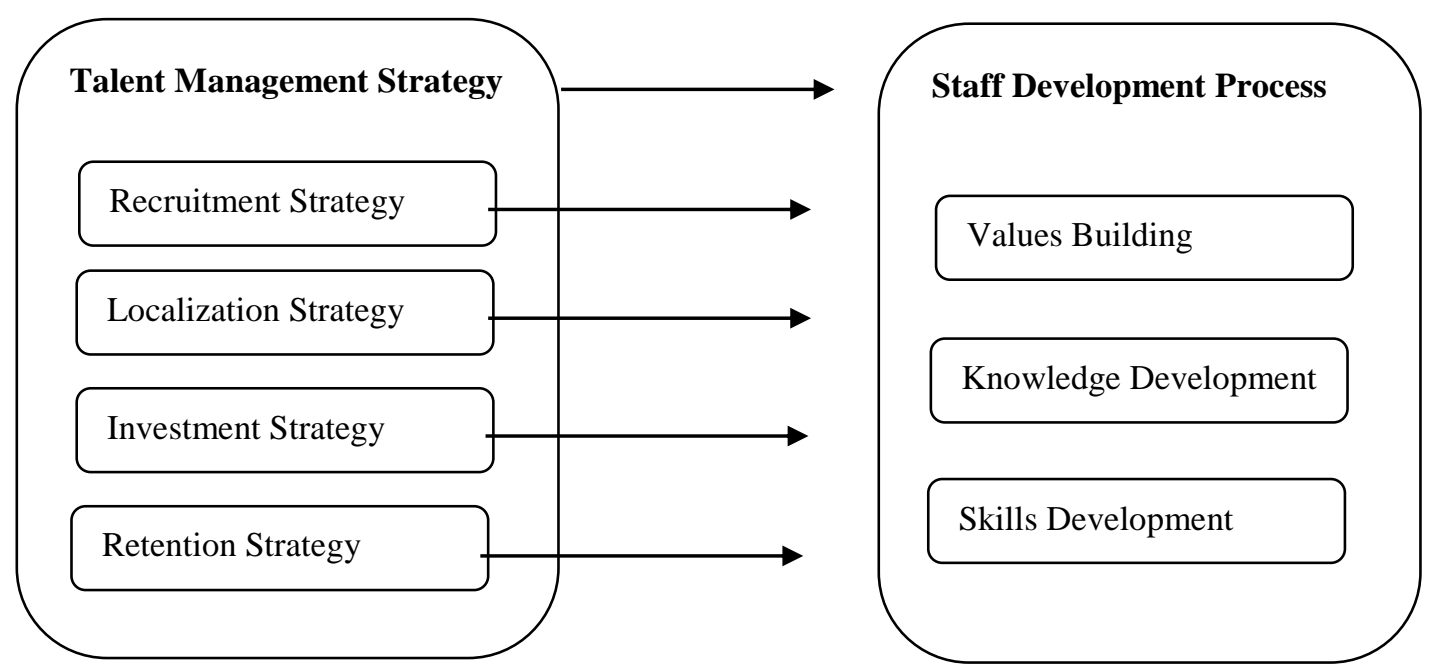

Source: Prepared by the researchers based on (Sail \& Alavi, 2010), (Sing, 2011), (Dessler, 2004) and

(Assaf, 2012).

\section{Hypotheses of the study}

The main hypothesis $\left(\mathrm{H}_{0} 1\right)$ :

There is no statistically significant effect of a significance level $(\mathrm{P} \leq 0.05)$ of the talent management strategy in terms of the significance of its dimensions (recruitment, localization, investment and retention), on the process of staff development in terms of the significance of its dimensions (values building, knowledge development and skills development) in Jordan Islamic Bank.

Sub-hypotheses:

The first hypothesis $\left(\mathrm{H}_{0} 1-1\right)$ : There is no statistically significant effect of a significance level $(\mathrm{P} \leq 0.05)$ of the recruitment strategy on the process of staff development in terms of the significance of its dimensions (value building, knowledge development, and skills development) in Jordan Islamic Bank.

The second hypothesis $\left(\mathrm{H}_{0} 1-2\right)$ : There is no statistically significant effect of a significance level $(\mathrm{P} \leq 0.05)$ of the localization strategy, on the staff development in terms of the significance of its dimensions (values building, knowledge development, and skills development) in Jordan Islamic Bank.

The third hypothesis $\left(\mathrm{H}_{0} 1-3\right)$ : There is no statistically significant effect of a significance level $(\mathrm{P} \leq 0.05)$ for the investment strategy, on the process of staff development in terms of the significance of its dimensions (values building, knowledge development, and skills development) in Jordan Islamic Bank.

The fourth hypothesis $\left(\mathrm{H}_{0} 1-4\right)$ : There is no statistically significant effect of a significance level $(\mathrm{P} \leq 0.05)$ of the retention strategy on the process of staff development in terms of the significance of its dimensions (values building, knowledge development, and skills development) in Jordan Islamic Bank.

\section{Previous Studies}

There is a variety of previous studies on the subject of talent management or the subject of the staff development in a way that makes it difficult to cover in a study like this. One of the latest such studies is that of (Hosen, Islam, Arshad, Khan \& Allam, 2018), entitled (Talent Management: An Escalating Strategic 
Focus in Bangladeshi Banking Industry). This study concludes that varying talent management practices in the banking sector are focused on attracting talent from sources outside the country more than internal sources. Moreover, it concludes that the banking sector is weak in providing retention practices such as knowledge management, incentive system and utilization of a culture of talent development. Another study is that of (Borisova, Silayeva, Saburov, Belokhvostova \& Sokolova, 2017), entitled (Talent Management as an Essential Element in A Corporate Personnel Development Strategy).

The study finds that the reason for the inability of Russian companies to retain talent is the negligence of the implementation of the strategy of talent management that is effectively applied in European and American companies. Moreover, the study of (Vnoučková, 2016), entitled (Practices of Talent Management in Organizations in The Czech Republic) concludes that the Czech companies need to strengthen their management practices to align with internal strategy and harmony as well as cultural integration and involvement in management. It also concludes that the talent management implementing of Czech companies are three types: first, the original implementing of talent management at $25.9 \%$, second, implementing through the learning-teaching system by involvement at $(23.5 \%)$, and third, the implementing through informing and promises without any practical practice. There is also the study of (Nasyira \& Ghazali, 2014), entitled (Predictors of intention to stay for employees of casual dining restaurant in Klang Valley area). It concludes the important role of support and organizational commitment to maintaining talented people.

The study of (Oladapo, 2014), entitled (The Impact of Talent Management on Retention), concludes that $70 \%$ of the surveyed American companies consider that talent management strategy is the most important factor for maintaining staff. The study concludes that the main reason for not implementing this strategy is the weakness of the support of the executive management and that job security and fair compensation are opportunities to improve the development of this strategy. The study of (Suhasini \& Naresh, 2013), entitled (Retention Management; A Strategic Dimension of Indian IT Companies), concludes that workers are not satisfied with the culture of the organization and the compensation systems in it, and that working on developing the functional policies and staff development are amongst the most important factors to preserve them. The study of (Noori \& Bezanaj, 2013), entitled (Talent Management Strategy in Iranian Private Sector Banking Strategic), concludes that talent management needs to develop the status of commitment and responsibility of staff, which requires the development of the systems and policies related to the staff and the process of their development.

The study of (Siam, 2013), entitled (The Reality of the Application of the Human Talent Management System from the Point of View of the Middle and Higher Management: A Case Study of the Islamic University in Gaza Strip), concludes that there is a lack of clarity about the concept of talent management, and a lack of organizational culture to focus on it. The study of (Kehinde, 2012), entitled (Talent Management; Effect on Organizational Performance in Nigerian Companies), concludes that the talent management system has a positive impact on the overall performance of the various organizations surveyed, and that there is a lack of the talent management concept among managers in small and medium enterprises. The study of (Hijazi and Eid, 2012), entitled (Talent Management: Assessing the knowledge of Lebanese employees), finds that there is a high level of talent management knowledge and that there is no serious strategic talent management work in most of the organizations surveyed. The study of (Al-Humaidi and Al-Tayeb, 2011), entitled (Investment in Training and Talent Management - Experience of the United Arab Emirates), finds that talent management has a strategic role in developing human resources in all the government and private sectors.

\section{Methodology of the study}

The study adopts the descriptive and the analytical methods, and it is a case study of Jordan Islamic Bank. The study population includes the directors of the Bank's branches in Amman, which are 30 branches. The study is based on surveying and it includes all the members of the society. A questionnaire was designed 
for the purposes of this study. It was distributed to all the sample members and a total of 24 forms were obtained, which is a percentage of $80 \%$. The five-dimensional Likert scale was used, and the appropriate statistical analysis was conducted to test the hypotheses of the study.

\section{Conceptual Framework}

\section{Talent Management Concept}

The concept of talent management is not really a new one, in the sense of the word, in human thought in general, or in administrative thought, in particular (Chuai, Preece \& Iles, 2008). We can say that the movement of human civilization as a whole is, in fact, the movement of talented people, and that the accumulation of human talent is the result of the accumulation of human civilization according to the stages of development, at any level, and in any area of human life, either in the materialistic, physical, chemical or biological area, or in the aspects of humanities: social, cultural, political, economic or administrative. The prevalence of this concept and the proliferation of its uses in the recent period are due to important reasons. These reasons are (Richard, 2008 ; Shaikh, 2007).

First: The role of organizations in the management of contemporary life in most societies has increased greatly. The contemporary societies can be described as the societies of organizations, with their different fields of specializations and activities, and their different levels of spread as well as their different sizes.

Second: The competition and conflict between organizations have unprecedentedly intensified, especially in the post-globalization era, which has become a distinct situation, following the incredible technological developments in the past few decades. The manifestations of the global economic war have become the dominant manifestations of international relations in general, and at the local levels among the organizations within each society in particular. This has led each organization to search for competitive advantages.

Third: Competition and conflict have become focused on the human resource, being the essential and decisive factor for any organization to achieve its goals of survival and upgrading. That is depending on the nature of these resources and the extent of their excellence, as well as their flexibility in dealing with the global developments and assimilation, in addition to studying the processes of dealing with them effectively.

This led the organizations to raise their interest in attracting the distinguished human resources and the necessary capabilities, as well as raise the level of interest in building the development strategies for the available human resources working for them, so as to improve their scope and capabilities. This has also led to the expansion of the area of competition and conflict between organizations, beyond the hubs of traditional competition and conflict. It has become primarily focused on their ability to attract and retain distinguished and talented workers. This has led to the emergence of what can be called terminologically: Talent War, prompting the organizations to adopt strategies for the management of this war, as determined by their vision and means.

\section{What does talent mean?}

God Almighty is the Creator and the Giver. When He created all the beings, He gave them all their structural, functional and kinetic attributes and characteristics. He made them varied, each of which has its own distinct character. Hence, they are all talented beings. The most important thing to mention is the instinctive talent. In all kinds of animals and their factions, and without any exception, God Almighty distinguished them with their instincts. He made their instincts impressively transparent so that they would resort to them in all aspects of their life with functional and kinetic precision. 
It is also the same with the divine gifts for mankind. The greatest of these talents is the Mental Talent, which distinguishes them from the rest of the beings. It represents the basis that governs their lives, controls their instincts, and guides their movement (their behavior) as they exercise their various functions. As the degrees of instinctive transparency among animals vary, the gifted mental energies of humans are also varied. They are enormous energies in their diversity and enormous in their limits. As scientists say, if one is able to use his mental energy more energetically like Einstein, for example, and for a hundred years (assuming that his lifespan is 100 years), he may use about $10 \%$ of his mental energy (Shrimali \& Gidwani, 2012).

In Addition, the other structural variations and other structural differences, represented in the different instinctive, emotional or physical elements, lead to the differentiation of some people from each other and to a degree that highlights their physical, emotional or instinctive talents in varying degrees as well.

The disparity in energies and the difference in capacity are the basis for the disparity in talent. If one or some individuals have one or some of the energies or abilities that appear to be high, these are regarded as indicators that they are more talented than others, or that they are as talented as other talented people like them, so they, and those who are like them, are referred to as talented, whereas others are not called the same. The talent is the expression of a high degree of differentiation in one or some of the abilities, energies, characteristics or qualities. It is the source of added value for any individual, compared to others who do not have this talent, and it is also the main source of added value for the organizations.

In order to clarify the definition of the term talent, we can read many definitions in this area, we find that they revolve around the following elements (Shrimali \& Gidwani, 2012;Goffee \& Jones, 2009;Shaikh, 2007).

1) The talent is an individual case related to the character of each individual and it depends, in terms of its quality, depth, and comprehensiveness, on the nature of this character, and the extent of the inherited or acquired characteristics. Talent is not related to instinct alone and is not based on the process of upbringing alone. It is the outcome of a deep and comprehensive interaction between these two cases.

2) The center of talent, whatever its nature, is in the brain, whether it is a mental talent or not. It is related to the mental, intellectual and methodological abilities ... etc., or a physical talent related to the linguistic, artistic or mathematical abilities ...etc. It is, in fact, the expression of a high level of intelligence in a given subject: so in the subject of mathematics, talent is the expression of a high level of intelligence in mathematics; In the subject of music, it is the expression of a high level of intelligence in the subject of music, and so is the case in the expression of any skill of the scientific or technical, athletic or administrative skills, etc.

3) The talent is not related to the knowledge system of a specific individual alone, or to the system of skills alone, or to the mental, physical or psychological state only. It is the outcome of the interaction of all this within the time and within objective context that ensures its emergence and guarantees its expression and utilization. It also allows handling it to develop and upgrade it.

4) Talent is a partial condition, and it relates to one or some of the abilities or energies or characteristics or qualities. So, talents vary in terms of fields, and degrees. Thus, a talented person in a particular field cannot claim to be the only one gifted or talented, because the wisdom of God in His creation has it some individuals are distinct and different, and each has their own energies and abilities. If the talents are rightfully nurtured, they will turn into energy and ability that are enough to raise their owner to become talented.

5) Talent is related to the ability to express it. Otherwise, it remains a hidden, valueless gift. This prompts the organizations to detect, nurture, develop and upgrade them, as well as invest in them by providing the requirements that would enable them to express themselves at the appropriate times and places. Based on this understanding, we can define talent as a unique state that stems from the character of each individual and its center is in the brain. It is an expression of a high level of intelligence in any given subject and it relates to one or some of the abilities, energies, properties or qualities that give the 
concerned individual an added value that he can invest in on his own, or the organization to which he belongs to, can invest in it to serve its interests.

\section{Talent Management Strategy}

There is no doubt that the use of the concept or term of strategy by any organization is a very important step, which, if managed accurately in the right direction, ensures the achievement of the goal of upgrading the organization and its capabilities to achieve success. Talents studying strategy has two requirements. They are as follows (Wheelen, Hunger, Hoffman, \& Bamford, 2017;Wilcox, 2016;Sweigart, 2015; Oladapo, 2014).

\section{First requirement: Meeting a number of basic conditions:}

First: It is important to realize that the strategy is a plan of action that has its specificity, which requires the utilization of all the necessary energies and capabilities because it is the key on which the achievement of success depends, and misuse will inevitably lead to failure and perhaps, to collapse. The most important characteristic of the strategy is that it is based on a clear and comprehensive understanding of the message of the organization, and the message of the organizational units related to it.

Second: It is important to recognize that talent management is a partial strategy within the HR strategy as a whole, which is a sub-strategy within the framework of the organization's strategy while emphasizing that any conflicts in this area are an indication of a strategic imbalance that must not be tolerated or accepted.

Third: It is important to realize the fact that any strategy, even if it is partial or subsidiary, must be marked by the following:

A- The rationality that ensures the rationalization of all the steps and this means the need to obtain reliable and certain information about all the elements and components that are considered in building the strategy; it is not permissible to rely on assumption, guess or intuition, except in cases where information is not available for one reason or another.

B- Comprehensiveness that ensures that all the factors or variables related to talents are considered and that any neglect or forgetfulness of any variable may spoil the entire strategy.

\section{The second requirement: It includes the following}

First: Identifying the actual needs of the talents required for the organization in all their variations or classifications; this requires the objective and systematic study of these needs, considering the financial and future conditions of the organization as determined by the overall strategy of the organization.

Second: Identifying, developing, and re-establishing the discovery strategy of internal talent, based on the results of the needs identified in the previous point, as a first priority before embarking on the next strategy Third: Identifying a strategy to attract talent from the market, within the determinants of the needs indicated in the first point; it should be noted here that attracting talent is not an end in itself; it must be within the framework of the actual needs of the organization, as defined by its strategy, given the cost of these talents, which are high by nature.

Fourth: Identifying a localization and an assimilation strategy of the talent recruited from outside the organization, and this means that:

1) Value and cultural harmony between the values and culture of the recruited talents and the values and culture of the organization.

2) Placing the required talent in the required location, and in the required post. 
Fifth: Identifying the strategy of investment in the different talents, as any talent is a high cost to the organizations, both in terms of the processes of discovery or recruitment or in terms of employment and localization, and the organizations should work to invest in them by identifying their added value, and the scenarios and policies that are necessary to operate them on the sites where they are recruited, so as to utilize them.

Here, we should warn against the perception of talent in organizations as mere cosmetic and publicity tools of the organizations, and if this happens, the expected benefits of recruiting and employing them will turn to the opposite. Six: Defining the talent retention strategy, especially in this general climate where the talent war has become a reality in today's competitive world.

Hence, each organization is aware of its circumstances, abilities, and options. Therefore, it must define its methods to retain its talents accordingly. It is, therefore, expected that these methods, and hence the strategies, will vary from one organization to another, or from one society to another (Poorthosseinzedeh \& Subramaniam, 2013).

It is pointed out that the Japanese strategy is based on granting trust and commitment to employees. The Italian strategy is based on evaluating performance and valuing the highest results. The Canadian strategy is based on the system of compensation and benefits throughout the work and post-retirement stages.

Seven: Planning the career path, which is one of the most important concerns of talented employees because they see that the benefits of career advancement are more important than the direct benefits and compensation, be they material or moral. That is because it includes the satisfaction of the professional, psychological and social aspirations, in addition to the consequent doubling of the material returns and benefits. Thus, organizations should clarify their career paths to be truly attractive to talents from abroad and to retain and satisfy the internal talents.

\section{Developing and improving the quality of employees as a foundation in the total quality management:}

There is no doubt that the philosophy of TQM since its inception and through all the stages of its development and its applications has focused on training and developing staff in all the elements of the system and at all the administrative levels of business organizations. The interest in staff training and developing their skills as well as improving their quality are stated in most of the (14) points mentioned by Deming to achieve total quality (Deming, 1986). All the comprehensive quality models, as well as the quality and excellence awards in the world, dedicated a special axis to developing staff and to measuring their performance. (Grigg \& Mann, 2017).

Total quality management focus on staff development is in line with the UNDP focus on the staff development and improvement of their quality in different organizations in general. This focus is reflected in its reports starting from 1990, which accorded particular attention as well as a special and intense focus. It expanded its perspective on this concept, saying that it includes: (Assaf, 2012).

First: The process of enlarging people's choices, whether these options are related to the health aspects, and their demand to live longer, healthier lives, or the educational aspects and their demand to have educational opportunities at all levels of education, or economic aspects and their demand of the availability of a reasonable standard that fulfills their needs, or social aspects and their demand of justice, political and social freedom, as well as ensuring their human rights, respect for themselves and their energies are preserved, so as to be good citizens and to be creatively productive.

Second: the process of developing the abilities and potential of staff up to special qualities so that they are able to achieve their developmental aspirations and demands. That is because the overall civilizational development does not realize itself on its own; the developmental will must be there in the humans in any 
society, especially among the public political leaders that work on the development of these human beings, within specific strategies for human development, to express this developmental will through a developmental performance that fits all the demands and aspirations.

\section{Axes of Staff Development: (Biech, 2015)}

The processes of human resources development focus on human, whether in his image as an individual or as a member of a group, and whether the group is small or large, social or professional, in the form of an organization, society or state. These processes are usually focused on the human character, being the entity through which human expresses his existence and behavior.

There is no doubt that human cultures and behaviors are determined according to the nature of their characters. Thus, the main objective of staff development is to deal with this character in order to achieve several demands:

(A) To promote personal qualities and behaviors appropriate to the aims, objectives, and methods of the organizations ... etc.

(B) To modify the personal characteristics and behaviors that appear to be appropriate to the aims, objectives, and methods of the organizations.

(C) To change the personal characteristics or behaviors that are inappropriate for the aims, objectives, and methods of the organizations.

(D) To develop and create personal characteristics, or new behaviors, that appropriate to the aims, objectives, and methods of the organizations.

Regardless of the details of these demands, it can be said that the fulfillment of any of them must be assumed to deal with the entire system of the human personality system because this cannot be fragmented practically. This also assumes the need to pay attention of all subsystems to develop them in line with these demands. This includes three major processes: (Assaf, 2012;Obryan, 2017).

(1) The pedagogical process, which focuses on the value system and the related social customs and traditions in order to develop and refine the value identity of the staff so as to make it compatible with the general philosophy and beliefs of the society or the organization; this philosophy or beliefs must be chosen with great awareness and precision, an open mind, and a comprehensive and sharp vision so as to create the targeted development philosophy and beliefs.

(2) The educational process, which focuses on the prevailing methods and approaches of thought, to instill a rational and scientific methodology that is capable of moving staff from the pre-conceived ideas, and the emotional, imaginary or delusional attitudes ... etc., to realistic and rational attitudes and practices; it also aims to develop and organize knowledge, in keeping with the development requirements.

(3) The training process, which focuses on the physical, technical, intellectual and behavioral skills and abilities to develop the applied energy of the staff, to enable them to put all the knowledge they reach into practice, and hence, lead human to the age of technology, and help him master it, and contribute as a partner to the movement and development processes of the age.

The different developmental studies, as well as other interesting studies, point to the importance of these three processes. Dr. Hassan Saab stresses that the progress required in the different societies is achieved only by the presence of the dynamic mind (the new development mind). He indicates that the scientific progress is not merely a factor in development but it is also a prerequisite for the economic growth in the first place (Saab, 1992).

The Director-General of UNESCO notes in his report that the human society is undergoing a vast and unprecedented transformation of population, technology, thought and ethics. The fundamental change in the policy and methods of education and culture lies at the heart of this process, and the path of this 
transformation depends mainly on it. This is confirmed by the International Committee for the Development of Education (Edgar Faur Committee), noting that the task of modern education is concentrated on the preparation of societies that have not come yet (Abu Zeid, 1994, 969-972).

Joseph Bognar says: "The importance of science in the modern world is not only in the way it seeks to find the truth but also in the formulation of a precise strategy for human activity, the role that scientists have in decision-making and the different policies is the best proof for that." (Bogner, 2011, p. 63).

Regarding the importance of training, Overton Jr. indicates that Middle Eastern countries have failed to adequately understand the fact that the human resource development requires the concerned country to pay attention to training as well as to education in terms of manpower because education and training are complementary processes. Thus, a country must recognize the fact that education does not substitute training, and that the necessary steps must be taken to balance them. (Assaf, 2012).

Given this intense focus on the importance of science, education, and training ... etc., questions have arisen about how important this is in the field of investment. Most studies in this field confirm that investments in the human element are absolutely productive and profitable investments. In a study conducted by Theodore Schultz in America, it appears that education costs have increased production a lot. The dollar that is invested in this field will often lead to an increase in the national production that exceeds the increase coming from the dollar invested in dams, machines, etc (Polk, 2013).

This human development trend supports the intensification of the contemporary global competition and its concentration on the human element, as well as the methods of its development and construction in a manner that ensures the mobilization of effective human power and energy, as Lodge, Professor of management at Harvard University says: The forces of competition previously concentrated on natural resources, capital and wealth, or technology, but for the contemporary developments, especially in the field of technology in the new institutions, these elements work together to fundamentally change these traditional factors of differentiation and competition. Natural resources turn upside down, putting the technology of production in a secondary position, compared with the technology of the new processes. Hence, skills, education, and knowledge of the workforce have become the first competitive weapon (Thurow, 2009).

According to Ichi \& Arthur, the factors that enable global business organizations to compete are numerous and complex and are no longer the traditional factors. (Ichi and Arthur, 1984: 3) The real competition nowadays is concentrated in a very sensitive area, which is the ability of the media, staff, and managers to create a social environment that organizes them during work, which requires a radical change in the values and beliefs (Thurow, 2009).

Consequently, there are significant and fundamental consequences for the culturing, education or training institutions, as well as for the managers of these institutions, and on the departments of pedagogical, educational or training operations, the most important of which are: (researcher).

A) Determining the philosophical value choices in a comprehensive, non-selective and organized manner, and forming a value system, not just a group of values, and then building the educational strategy that achieves it.

B) Changing the traditional and primitive concepts of education, and realizing that it is not just the circulation of knowledge as is common in most of our school and university institutions, and knowledge must be put in appropriate, developed and constantly evolving implementation contexts throughout its circulation or presentation.

C) Changing the primitive and false understanding of most institutions that request training, and which is common amongst some of those responsible for the training process in public or private sector organizations, that there is no need to present knowledge, ideas or scientific theories in the training, 
and that the focus should be mainly on practical applications; skill that is not based on scientific knowledge is superficial.

D) Being keen on putting a strategy in place to achieve the integration of value education processes, knowledge development, and technical skill development, in order to:

- The philosophies or beliefs, which provide systems of values, rules, and ideas, provide in fact perceptions of how the society, organization or individual who embraces them, should be like. This is the ground from which the educational process is launched. Thus, they represent a framework of movement within which they organize themselves, and the other processes work for reinforcing them. Hence, they make the basis of the (triangle) on which the other sides rest. Any education or training must consider the educational laws, and it must be keen to consolidate and develop them. Otherwise, it will lose the base to which it is directed and turn into a charade.

- The systems of scientific knowledge and methods do not represent an end in themselves. Human is the one who exerts all the scientific, intellectual and creative effort. He does not do so just to reach a scientific idea, basis or invention only. Yet, it is the function of human successor over history. Since his creation, Man has this urge to exert all this scientific effort to be its guide and help to develop his life in terms of his relation with nature, or with other human beings, and to be able to build this universe. Therefore, knowledge must be placed in an implementation context in order to take its place in the context of life and history. Otherwise, it will remain as fictitious knowledge, canned in the head of its holder, or between the covers of a book or in a manuscript. Thus, it will lose its function, and subsequently its value, until it is re-established in that context. Perhaps the most important thing that helps to put knowledge in implementation context is working to match them with the training process that enables the building of the necessary practical skills.

And you can say the same about the training process as it cannot focus on applied skills, no matter what they are, apart from the cognitive context of these skills. Otherwise, they would be random and primitive skills. The bottom line: Education and training are fundamental processes that interact with the system of values sought by the individual, the organization, or the nation, and they work on building the human character and the development of its quality.

\section{Result and Discussion}

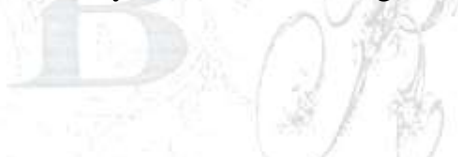

First: Multiple linear correlation tests were carried out to ensure the suitability of the study model. The results were as follows:

Table (1) Multiple linear correlation test

\begin{tabular}{|c|c|c|}
\hline Sr. No. & Variables & Variance inflation factor VIF \\
\hline 1 & Recruitment Strategy & 2.767 \\
\hline 2 & Localization Strategy & 3.336 \\
\hline 3 & Investment Strategy & 2.155 \\
\hline 4 & Retention strategy & 1.988 \\
\hline
\end{tabular}

As noted, all the results of the variance inflation coefficient are higher than one and less than ten, which is confirmed by (Gujarati, 2004, 352). There is no problem with the study variables.

Second: The self-correlation test (Durbin-Watson statistic) was performed to ensure that the data were free from the self-correlation problem. The results were as follows:

As noted, all the values of (d) are outside the limits of the standard values specified in (dL), and in(du), which confirms the absence of self-correlation in the data and their validity in the uses of the regression model. 
Table (2) Self - correlation test

\begin{tabular}{|c|c|c|c|c|}
\hline Hypothesis & $\begin{array}{c}\text { Values (DW) d } \\
\text { Calculated }\end{array}$ & $\begin{array}{c}\text { (dL) Minimum } \\
\text { limits }\end{array}$ & $\begin{array}{c}\text { (du) Maximum } \\
\text { limits }\end{array}$ & Conclusion: \\
\hline $\mathrm{H}_{0} 1-1$ & $1.8 \mathrm{o} 3$ & 1.758 & 1.779 & There is no self-correlation. \\
\hline $\mathrm{H}_{0} 1-2$ & 1.812 & 1.758 & 1.779 & There is no self-correlation. \\
\hline $\mathrm{H}_{0} 1-3$ & 1.852 & 1.758 & 1.779 & There is no self-correlation. \\
\hline $\mathrm{H}_{0} 1-4$ & 1.905 & 1.758 & 1.799 & There is no self-correlation. \\
\hline $\mathrm{H}_{0} 1$ & 1.889 & 1.728 & 1.809 & There is no self-correlation. \\
\hline
\end{tabular}

Third: the study hypotheses were tested. This was done by analyzing the simple and gradual linear regression. The results were as follows:

$$
\text { The first sub-hypothesis test }\left(\mathrm{H}_{0} 1-1\right) \text {, and the result is as follows in Table (3) }
$$

Table (3) Results of the test of the recruitment strategy impact on staff development

\begin{tabular}{|c|c|c|c|c|c|c|c|c|c|c|}
\hline \multirow{2}{*}{$\begin{array}{c}\text { Dependent } \\
\text { variable: }\end{array}$} & \multicolumn{2}{|c|}{ Model Summary } & \multicolumn{3}{|c|}{ ANOVA } & \multicolumn{5}{|c|}{ Coefficient } \\
\hline & $\begin{array}{c}\text { r Correlation } \\
\text { coefficient }\end{array}$ & $\mathrm{r}^{2}$ & $\begin{array}{c}\text { Calculated } \\
\text { F }\end{array}$ & $\begin{array}{l}\text { Df Degree } \\
\text { of freedom }\end{array}$ & Sig F & Description & B & $\begin{array}{l}\text { Standar } \\
\text { d error }\end{array}$ & $\begin{array}{c}\text { Calculate } \\
\text { d T }\end{array}$ & Sig T \\
\hline \begin{tabular}{|l|} 
Staff \\
Development
\end{tabular} & 0.692 & 0.479 & 217.945 & 1 & 0.000 & Recruitment & 0.567 & 0.038 & 14.763 & 0.000 \\
\hline
\end{tabular}

As noted, the value of the correlation coefficient ( $r$ ) between the recruitment strategy variable and the staff development variable is positive and high by standard (Zikmund, 2000, 513). It also appears that the selection coefficient $\left(\mathrm{r}^{2}\right)$ explains the role of the recruitment strategy in staff at a level of variation of $(47.9 \%)$, with other variables remaining constant. The value of $(\mathrm{F})$ confirms the significance of the regression at a level of less than $5 \%$, and at a level of confidence of $(\mathrm{Sig}=0.000)$. The rest of the results confirm the significance of the labs at a level of less than 5\%. This leads to the refutation of the first subhypothesis and acceptance of the hypothesis (that there is a significant statistical effect at a level equal to or less than $5 \%$ for the recruitment strategy on the staff development process in Jordan Islamic Bank).

(2) The second sub-hypothesis test $\left(\mathrm{H}_{0} 1-2\right)$, and the result is as follows in Table (4)

Table (4) Results of the test of the localization strategy impact on staff development

\begin{tabular}{|c|c|c|c|c|c|c|c|c|c|c|}
\hline \multirow{2}{*}{$\begin{array}{l}\text { Dependent } \\
\text { variable: }\end{array}$} & \multicolumn{2}{|c|}{ Model Summary } & \multicolumn{3}{|c|}{ ANOVA } & \multicolumn{5}{|c|}{ Coefficient } \\
\hline & $\begin{array}{c}\text { r Correlation } \\
\text { coefficient }\end{array}$ & $\mathrm{r}^{2}$ & $\begin{array}{c}\text { Calculated } \\
\text { F }\end{array}$ & $\begin{array}{l}\text { Df Degree } \\
\text { of freedom }\end{array}$ & Sig F & Description & B & $\begin{array}{l}\text { Standar } \\
\text { d error }\end{array}$ & $\begin{array}{c}\text { Calculate } \\
\text { d T }\end{array}$ & Sig T \\
\hline \begin{tabular}{|l} 
Staff \\
Development
\end{tabular} & 0.731 & 0.534 & 272.123 & 1 & 0.000 & Localization & 0.595 & 0.036 & 16.496 & 0.000 \\
\hline
\end{tabular}

As noted, the correlation coefficient between the localization strategy variable and the staff development variable is $(73.1 \%)$, which is positive and high by standard (Zikmund, 2000, 513). The selection coefficient $\left(\mathrm{r}^{2}\right)$ explains the role of the localization strategy in staff development at a variation level of 53.4\%, with other variables remaining constant. The value of $(\mathrm{F})$ confirms the significance of the regression at a level of less than $5 \%$, and at a level of confidence of $(\mathrm{Sig}=0.000)$. The rest of the results confirm the significance of the labs at a level of less than 5\%. This leads to the refutation of the second sub-hypothesis and acceptance of the hypothesis (that there is a significant statistical effect at a level equal to or less than $5 \%$ of the localization strategy on the staff development process in Jordan Islamic Bank). 
Table (5) Results of the test of the investment strategy impact on staff development

\begin{tabular}{|l|c|c|c|c|c|c|c|c|c|c|}
\hline $\begin{array}{c}\text { Dependent } \\
\text { variable: }\end{array}$ & \multicolumn{2}{|c|}{ Model Summary } & \multicolumn{4}{c|}{ ANOVA } & \multicolumn{5}{c|}{ Coefficient } \\
\cline { 2 - 11 } & $\begin{array}{c}\text { r Correlation } \\
\text { coefficient }\end{array}$ & $\mathrm{r}^{2}$ & $\begin{array}{c}\text { Calculated } \\
\mathrm{F}\end{array}$ & $\begin{array}{c}\text { Df Degree } \\
\text { of freedom }\end{array}$ & Sig F & Description & $\mathrm{B}$ & $\begin{array}{c}\text { Standar } \\
\mathrm{d} \text { error }\end{array}$ & $\begin{array}{c}\text { Calculate } \\
\mathrm{d} T\end{array}$ & Sig T \\
\hline $\begin{array}{l}\text { Staff } \\
\text { Development }\end{array}$ & 0.712 & 0.507 & 243.485 & 1 & 0.000 & Investment & 0.547 & 0.035 & 15.604 & 0.000 \\
\hline
\end{tabular}

As noted, the value of the correlation coefficient (r) between the investment variable strategy and the staff development variable is positive and high by standard (Zikmund, 2000, 513). The selection coefficient $\left(\mathrm{r}^{2}\right)$ explains the role of the investment strategy in staff development at a variation level of (50.7\%), with other variables remaining constant.

The value of (F) confirms the significance of the regression at a level of less than 5\%, and at the level of confidence of $(\mathrm{Sig}=0.000)$. The rest of the results confirm the significance of the labs at a level of less than 5\%. This leads to the refutation of the third sub-hypothesis and acceptance of the hypothesis (that there is a significant statistical effect at a level equal to or less than $5 \%$ of the investment strategy on staff development in Jordan Islamic Bank).

\section{The fourth sub-hypothesis test $\left(\mathrm{H}_{0} \mathbf{1 - 4}\right)$, The result is as follows in Table (6)}

Table (6) Results of the retention strategy impact on staff development

\begin{tabular}{|l|c|c|c|c|c|c|c|c|c|c|}
\hline $\begin{array}{c}\text { Dependent } \\
\text { variable: }\end{array}$ & \multicolumn{2}{|c|}{ Model Summary } & \multicolumn{3}{c|}{ ANOVA } & \multicolumn{5}{c|}{ Coefficient } \\
\cline { 2 - 11 } & $\begin{array}{c}\text { r Correlation } \\
\text { coefficient }\end{array}$ & $\mathrm{r}^{2}$ & $\begin{array}{c}\text { Calculated } \\
\mathrm{F}\end{array}$ & $\begin{array}{c}\text { Df Degree } \\
\text { of freedom }\end{array}$ & Sig F & Description & B & $\begin{array}{c}\text { Standar } \\
\text { d error }\end{array}$ & $\begin{array}{c}\text { Calculate } \\
\mathrm{d} T\end{array}$ & Sig T \\
\hline $\begin{array}{l}\text { Staff } \\
\text { Development }\end{array}$ & 0.742 & 0.550 & 290.087 & 1 & 0.000 & Retention & 0.639 & 037.0 & 17.032 & 0.000 \\
\hline
\end{tabular}

As noted, the value of the correlation coefficient (r) between the retention strategy variable and the staff development variable is positive and high by standard (Zikmund, 2000,513). The selection coefficient $\left(\mathrm{r}^{2}\right)$ explains the role of the retention strategy in staff development at a variation level of (55.0\%), with other variables remaining constant. The value of $(\mathrm{F})$ confirms the significance of the regression at a level of less than $5 \%$, and at the level of confidence of $(\mathrm{Sig}=0.000)$.

The rest of the results confirm the significance of the labs at a level of less than 5\%. This leads to the refutation of the fourth sub-hypothesis and acceptance of the hypothesis (that there is a significant statistical effect at a level equal to or less than $5 \%$ of the retention strategy on staff development in Jordan Islamic Bank).

(5) The main hypothesis test and the determining which of the sub-variables has the highest impact on the process of staff development: The multiple gradient regression test was conducted, and the following table shows that:

By observing the data in Table (7), it appears that the first model of the gradual regression analysis shows that the retention strategy variable has been interpreted as (55) of the total variation in staff development. The percentage becomes 66.7 upon adding the localization strategy variable to the retention strategy variable, and percentage becomes 69.7 upon adding the investment strategy, to reach 70.7 by adding the recruitment strategy. 
Table (7): Summary of the model for testing the main hypothesis

\begin{tabular}{|c|c|c|c|}
\hline \multirow{2}{*}{ Form } & \multicolumn{3}{|c|}{ Form summary } \\
\cline { 2 - 4 } & $\begin{array}{c}\mathbf{R} \\
\text { Correlation } \\
\text { coefficient }\end{array}$ & $\begin{array}{c}\mathbf{r}^{\mathbf{2}} \\
\text { Determination } \\
\text { Coefficient }\end{array}$ & Standard error \\
\hline 1 & 0.742 & 0.550 & 0.504 \\
\hline 2 & 0.817 & 0.667 & 0.435 \\
\hline 3 & 0.835 & 0.697 & 0.416 \\
\hline 4 & 0.841 & 0.707 & 0.409 \\
\hline
\end{tabular}

Table (8) Variance analysis to test the main hypothesis

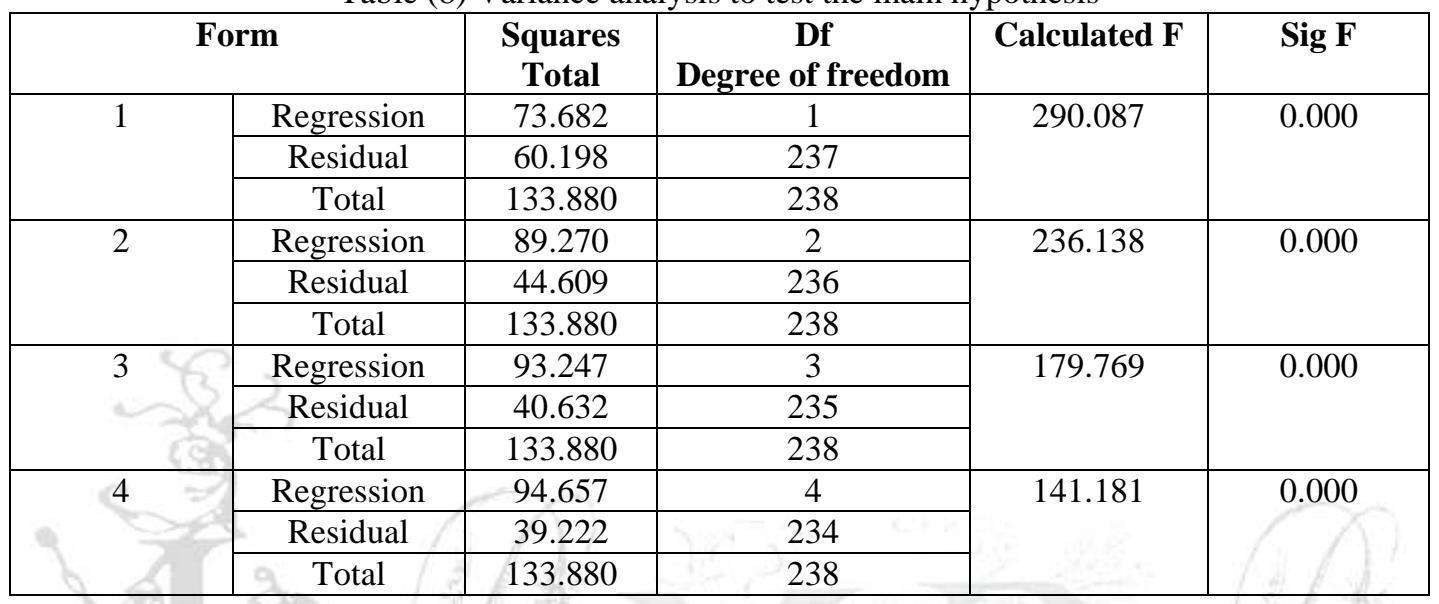

It also appears that the value of the (F) levels in all the models falls within a significant level of (Sig = $0.000)$ as shown in Table (9) below:

Table (9) Summary of the results of the regression coefficient for the main hypothesis test

\begin{tabular}{|c|c|c|c|c|c|}
\hline Form & $\begin{array}{c}\text { Employee } \\
\text { development process }\end{array}$ & B & Std. Error & $\begin{array}{c}\text { Values } \\
\text { Calculated }\end{array}$ & Sig t \\
\hline \multirow{2}{*}{ First } & Retention strategy & 0.639 & 0.037 & 17.032 & 0.000 \\
\hline \multirow{3}{*}{ Second } & Retention strategy & 0.402 & 0.042 & 9.680 & 0.000 \\
\cline { 2 - 6 } & Localization Strategy & 0.357 & 0.039 & 9.081 & 0.000 \\
\hline \multirow{3}{*}{ Third } & Retention strategy & 0.331 & 0.042 & 7.795 & 0.000 \\
\cline { 2 - 6 } & Localization Strategy & 0.258 & 0.043 & 6.013 & 0.000 \\
\cline { 2 - 6 } & Investment Strategy & 0.194 & 0.041 & 4.796 & 0.000 \\
\hline \multirow{3}{*}{ Fourth } & Retention strategy & $0.302 * * *$ & 0.043 & 7.020 & 0.000 \\
\cline { 2 - 6 } & Localization Strategy & $0.167 * * *$ & 0.053 & 3.167 & 0.002 \\
\cline { 2 - 6 } & Investment Strategy & 0.194 & 0.040 & 4.851 & 0.000 \\
\cline { 2 - 6 } & Recruitment Strategy & 0.140 & $0.048 * * *$ & 2.900 & $0.004 * * *$ \\
\hline
\end{tabular}

By observing these results, it appears that the (B) values in the different (t) models fall at the level of significance $(\mathrm{Sig}=0.004)$ or less. This confirms the significance of the regression coefficients, which confirms that the effect of the variables in those models is statistically significant. We, therefore, reject the main hypothesis and accept the alternative hypothesis that there is a significant statistical effect at a significant level of $\mathrm{P} \leq 0.05$ for the (recruitment, localization, investment and retention strategies) on the 
process of developing staff development in terms of its different dimensions (values building, knowledge development, and skills development) in Jordan Islamic Bank.

\section{Conclusions and Recommendations}

First: It turns out that there is an important role for the strategic talent management on staff development process in Jordan Islamic Bank, and there are subsidiary roles and tasks for each of the sub-strategies relating to the overall strategy such as the recruitment strategy, localization strategy, investment strategy and retention strategy. This calls for the need to develop a holistic strategy for talent management, which should include all the necessary arrangements to discover, recruit, localize and invest in talents as well as to work on ensuring their retention.

Second: The staff development process is complex and intricate. It includes all the elements of the human character, and it focuses on its minimum limits to develop three major systems; these are the values, knowledge and skills systems. This calls for the need to develop a development strategy that will achieve this.

\section{References}

Abu Zeid, A. (1994). Human Sciences and Ideological Conflict, World of Thought Magazine, Volume II, Ministry of Information, Kuwait, 969-978.

Al-Hamidi, M. Al-Tayeb, A. (2011). Investment in training and talent management: The experience of the United Arab Emirates, Research Paper, Ras Al Khaimah Police College, United Arab Emirates.

Assaf, A. M. (2012). Training and human resources development, Dar Zahran Printing \& Publishing, Amman.

Biech, E. (2015). Training and Development for Dummies, Hoboken, NJ: Wiley \& Sons.

Bogner, J. (2011). Economic Development in Developing Countries, Ahmed El Qaseer, Egyptian Book Association, Cairo.

Borisova, Oksana., Silayeva, Anna., Saburova, Larisa., Belokhvostova, Natalya., Sokolova, Antonina. Talent Management as An Essential Element in A Corporate Personnel Development Strategy, Academy of Strategic Management Journal, 16 (1).

Chuai, X., Preece, D. \& Iles, P. (2008). Is Talent Management Just Old Wine in New Bottle?, The Case of Multinational Companies in Beijing, Management Research News, 31 (12).

Dessler, Gary (2011) A Framework for Human Resources Management (6th ed.), USA, Pearson Education Publishing as a Prentice Hall.

Grigg, Nigel., Mann, Robin. (2017). Rewarding Excellence: An International Study into Business Excellence Award Processes. Quality Management Journal Volume 15 (3).

Gujarati, Damodar, N., (2004) Basic Econometrics, 4th ed. New York, The McGraw-Hill Co.

Hijazi, H., \& Eid, A. (2012) Talent Management: Assessing the knowledge of Lebanese employees, Journal of Administration and Social Sciences, Volume 2, Number 9, 24-45.

Hosen, Sharif, Islam, Md., Arshad, Mohd, Khan, Arif, \& Alam, Kausar (2018). Talent Management: An Escalating Strategic Focus in Bangladeshi Banking Industry. International Journal of Academic Research in Business and Social Sciences, 8 (1).

Ichi, Shin, Takezawa \& Arthur, M., Whitehill, (1984) Workways: Japan And America, The Japanese Institute of Labor.

Kehinde, James, (2012), Talent Management-Effect on Organizational Performance, Lagos State University, Nigeria West Africa, Journal of Management Research, 4 (2).

Nasyira, MN, Othman, MN, \& Gazali, H. (2014), Predictors of Intention to Stay for Employees of Casual Dining Restaurant in Klang Valley area, International Food Research Journal, 26 (45).

Noori, M., \& Bezanaj, AAM, (2013) Talent Management Strategy in Iranian Private Sector Banking Strategic, Interdisciplinary Journal of Contemporary Research in Business, 5 (4). 
OBryan, Chuck., \& Casey, Anne. (2017). Talent Management: Hiring and Developing Engaged Employees. Library Leadership \& Management, 32 (1). Retrieved from http://commons.erau.edu/publication/561

Oladapo, Victor. (2014). The Impact of Talent Management on Retention. Journal of Business Studies Quarterly, 5 (3).

Polk, William, ed. (2013), Development Revolution, North Africa, Middle East, \& Asia, Washington, D, C. Richard, E. Boyatzis, (2008) Competencies in the 21st Century, Journal of Management Development, 27 (1).

Saab, H. (1992). Man is capital, Journal of the World of the Jaw, Volume II, Ministry of Information, Kuwait, 1038-1052.

Sail, Rahim, \& Alavi, Khadijah, (2010). Social Skills and Social Values, Journal of European Industrial Training, Emerald Group, 34 (3).

Siam, A. \& Abdel, R. (2013). The reality of the application of human talent management system from the point of view of middle and upper management, Case Study of Islamic University in the Gaza Strip, Dissertated Master Thesis, Islamic University, Gaza

Sing, Narender, (2011). Human Resource Management, New Delhi University of Science Press.

Suhasini, N. Naresh Babu, T (2013), Retention Manukkkkkkk6agement; A Strategic Dimension of Indian IT Companies, International Journal of Management and Social Sciences Research, 2 (2).

Sweigart, Jon (2015), Talent Management in an Ownership Culture, The ESOP Reporter, February issue.

Thurow, Lester. (2009). Head to Head: The Coming Economic Battle among Japan, Europe, and America, Harper Collins.

Vnoučková, Lucie. (2016). Practices of Talent Management in Organizations in the Czech Republic. Acta Universitatis Agriculturae Et Silviculturae Mendelianae Brunensis,64 (2).

Wheelen, Thomas., Hunger, David., \& Hoffman, Alan \& Bamford., Charles. (2017). Strategic Management and Business Policy (15th ed). New Jersey: Pearson International Edition.

Wilcox, Mark. (2016). Effective Talent Management: Aligning Strategy, People and Performance (1st Edition). New York: Routledge Publishing.

Zikmund, William (2000), Business Research Methods, 6th ed., Fort Worth: Harcourt College Publishers. 